\title{
Estado del Cultivo de Plátano (Musa sp) en el Municipio de Tlapacoyan, Veracruz
}

\author{
Paloma V. Susan Tepetlan¹ - Juan C. Noa Carrazana² - Norma Flores Estevez ${ }^{3}$
}

\section{RESUMEN}

Los bananos y plátanos (Musa sp) se cultivan en más de 120 países alrededor del mundo y suministran una importante fuente de carbohidratos para más de 400 millones de personas en países tropicales, representan el cuarto cultivo de mayor importancia después del maíz (Zea mays), trigo (Triticum aestivum) y arroz (Oryza sativa). En México, se cultivan en 15 Estados, la variedad de bananos y plátanos que se cultivan es amplia, dentro de ellas destacan los bananos como el Plátano Tabasco o Roatán, Enano Gigante, Criollo, Valery, Dominico, Manzano y los plátanos Macho, Morado y Pera, entre otros. Veracruz, ocupa el tercer lugar a nivel nacional en su, después de Chiapas y Tabasco, produciéndose en zonas en las que el cultivo es una de las principales actividades.

\begin{abstract}
Bananas and plantains are grown in more than 120 countries around the world, provides an important source of carbohydrates for more than 400 million people in tropical countries, is the fourth most important crop after maize (Zea mays), wheat (Triticum aestivum) and rice (Oryza sativa). In Mexico, are grown in 15 states, banana and plantain cultivars that are grown is wide, within them we can found bananas as Tabasco or Roatán, Giant Dwarf, Macho, Criollo, Valery, Dominico, Manzano and plantains as Morado and Pera between others. Veracruz, is third in banana production, after Chiapas and Tabasco, taking place in areas where this crop is one of the main activities.
\end{abstract}

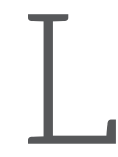

os bananos y plátanos son una especie tropical que se cultivan en alrededor de 120 países, siendo el cuarto cultivo de importancia a nivel mundial después del arroz, el trigo y el maíz. Aproximadamente 100 millones de toneladas de bananos y plátanos son producidas anualmente en todo el mundo, siendo los países africanos los principales productores de plátano, la mayor parte de esta producción es consumida localmente. En México se cultivan diferentes variedades de bananos y plátano en 15 estados, siendo Veracruz el tercer lugar en producción de banano. En nuestro estado, existen alrededor de 3,361 productores que se encuentran concentrados en dos áreas geográficas como la zona norte: que comprende los municipios de Martínez de la Torre, San Rafael, Tlapacoyan, Nautla, Vega de Alatorre, Atzalan, Gutiérrez Zamora, Papantla y Misantla y la zona Cuenca del Papaloapan: incluye los municipios de Otatitlán, Tlacojalpan, Tuxtilla, Chacaltianguis, Cosamaloapan y Tres Valles.

El municipio de Tlapacoyan, colinda al norte con el estado de Puebla y el municipio de Martínez de la Torre; al este con los municipios de Martínez de la Torre y Atzalan; al sur con los municipios de Atzalan, Jalacingo y el estado de Puebla; al oeste con el estado de Puebla. Ocupa el $0.23 \%$ de la superficie del estado, ubicado en las coordenadas $19^{\circ} 58^{\prime}$ latitud norte y $97^{\circ} 13^{\prime}$ 
longitud oeste, su altitud es de 650 msnm, su clima es cálidohúmedo con una temperatura promedio que varía entre los $22-24^{\circ} \mathrm{C}$. El suelo es de tipo luvisol, que se utiliza en agricultura y ganadería en $60 \%$.

Se tiene registro de que el cultivo de plátano de castilla y la naranja (Citrus $\times$ sinensis, (L.) Osbeck) se introdujo en esta región hacia finales del siglo XVI, junto con la producción de miel, algodón (Gossypium spp.) y caña de azúcar (Saccharum officinarum). Actualmente (2016) aproximadamente 2000 ha de la zona están dedicadas al cultivo de diversas variedades. Se reconoce que laboran en esta actividad, alrededor de 750 productores, con una superficie promedio de 1 ha por productor. De acuerdo al grado y tipo de tecnología empleado se distinguen dos tipos de productores: productor medio (aquellos que tienen 1-15 ha de cultivo) y productor de subsistencia (aquellos con 0.5-1 ha de cultivo). Se ha calculado que el valor de la producción agrícola total para el municipio es de $\$ 559,377.67$ pesos anuales. Después del limón (Citrus $\times$ latifolia, Tanaka), el cultivo de banano aporta una mayor cantidad de dinero a la producción agrícola total de la región, con $\$ 94,312.24$ pesos anuales.

En los trabajos realizados por el grupo de investigación del Instituto de Biotecnología y Ecología Aplicada (INBIOTECA) de la Universidad Veracruzana se observó que en el área de estudio el 80\% de los productores son hombres y el 20\% restante mujeres que se encargan en su totalidad del cuidado y manejo de la parcela. Los productores tienen 54 años de edad en promedio y alrededor de tres hijos. Se puede vislumbrar el cultivo de banano como una actividad legada de generación en generación de padres a hijos, pues algunas parcelas tienen más de 50 años produciendo. Los padres les inculcan el cuidado y manejo de la parcela a sus hijos desde muy temprana edad realizando actividades como limpieza, deshoje, deshije, fumigación, fertilización y cosecha de las unidades de producción de las parcelas (Fig. 1.A). Una forma de garantizar que continuaran haciendo adecuadamente su labor es enviándolos a la escuela para prepararse, sin embargo esto ocurre en una baja proporción, ya que los pro- ductores que cuentan con licenciatura como nivel máximo de instrucción es bajo alrededor de un $19 \%$.

Las variedades que más se cultivan y de las que se obtienen mayores ingresos enla zona de Tlapacoyan, Ver, son el banano cultivar Dominico (Musa AAB, Simmonds) en un 95\%, seguido por otros cultivares de plátano como el Morado, Bolsa, Macho y Blanco (genomas AAA, ABB, AAB y AAB respectivamente). Estas variedades se encuentran como monocultivos o intercaldas con cultivos de cítricos, café (Coffea arabica) e incluso algunas especies propias del bosque mesófilo como el chico zapote (Manilkara sapota), el mamey (Pouteria sapota) y la pimienta (Piper nigrum), de las cuales obtienen en ocasiones algunos ingresos extra, aparte de la venta de plátano. Al respecto, cabe mencionar que algunos productores obtienen las hojas de plátano Morado para ser comercializadas como velillo (rollos de hojas para tamal), que es llevado a la central de abastos en la ciudad de México (Fig. 1.B). Así mismo, existen además otras variedades de plátano que no son comercializadas y solo se utilizan como cultivos de traspatio, para consumo personal, tal es el caso del plátano Manzano, Bolzano, Guineo, Rombo, Tuna y Manila (genomas AAB, AAB, AAA, ABB, BB y AAB).

De manera general, los productores identifican tres enfermedades que afectan el cultivo de los diferentes cultivares de banano y plátano, se trata en primer lugar del "chamusco" o Sigatoka negra causada por el hongo Micosphaerella fijiensis Morelet, así como la zigatoka amarilla causada por Micosphaerella musicola Leach, y que a nivel mundial son una de las enfermedades que causan cuantiosas pérdidas económicas en las diferentes regiones productoras de bananos y plátanos. En segundo lugar, los nematodos, en este caso se trata del nematodo barrenador Radopholus similis, el cual ataca las raíces y el cormo de las plantas afectando su crecimiento y desarrollo. Finalmente las tuzas (Thomomys umbrinus) y el moco (causado por la bacteria Erwinia caratovora) que también afectan directamente raíces y cormos, a los que comúnmente se le denomina hijuelos.

Estás enfermedades son tratadas principal- 


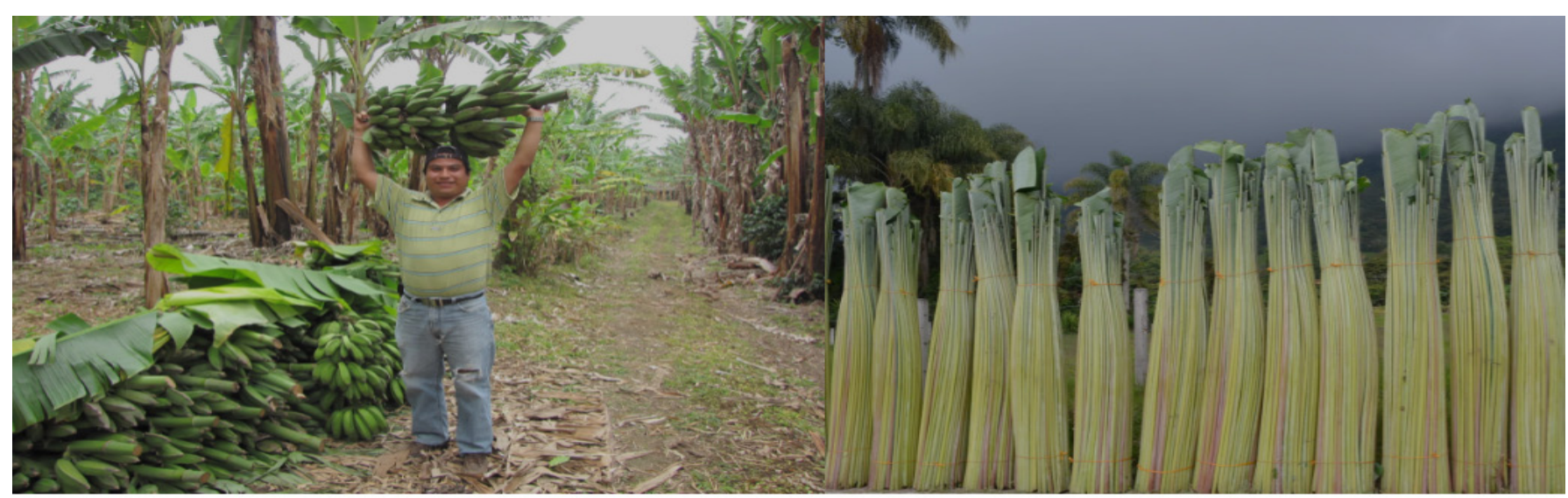

Figura 1. Corte de racimos de plátano en parcela de Tlapacoyan, Ver. B) Hoja comercializada como velillo.

mente con diferentes productos químicos, sin embargo no existe a la fecha ningún tipo de control biológico que pudiera ser implementado para eliminar o disminuir sus efectos sobre los cultivos. Por el contrario, existen algunas prácticas que favorecen la propagación de nematodos, así como de bacterias, nos referimos al uso de cormos o hijuelos. Los bananos y plátanos se reproducen a través de propagación vegetativa mediante el uso de cormos o hijuelos, los cuales son obtenidos de plantas madre, si dicho material se encuentra infectado con los agentes patógenos antes mencionados o inclusive otros agentes como los virus, fácilmente se van a propagar causando severos daños en el crecimiento y desarrollo de la plantas, así como en los frutos, lo cual se verá reflejado en la productividad de las parcelas a corto y largo plazo.

Una forma de tratar de reducir los efectos de las enfermedades en las parcelas ha sido el hecho de que la mayoría de los productores son integrantes de la Asociación de Productores de Tlapacoyan, esta organización promueve el apoyo, el manejo y control de enfermedades, así como la comercialización de su producción. Debido a que son muy pocos los productores que cuentan con un seguro agrario para evitar pérdidas económicas causadas por enfermedades como por diferentes eventos climáticos. A través del auspicio y vigilancia de la asociación se promueve el que los productores utilicen diferentes productos químicos para el manejo de las enfermedades, así como para dar a co- nocer las parcelas con algún tipo de problema fitosanitario para que los productores aledaños tomen las medidas necesarias.

Debido a lo anterior, podemos concluir que el cultivo de bananos y plátanos en el Municipio de Tlapacoyan, Veracruz, se encuentra profundamente arraigado entre sus pobladores, ya que es una actividad que lleva practicándose por más de 400 años, debido a que es considerada como una labor de tipo familiar. Los principales agentes causantes de enfermedades son hongos, nematodos y bacterias, que son controlados de manera química primordialmente. Una estrategia de control y combate de plagas y enfermedades por parte de los productores es el estar constituidos en una Asociación, lo que permite hasta cierto punto manejar y reducir los efectos de enfermedades como la sigatoka negra, así como definir los mejores canales de comercialización para su producción.

Con el fin de seguir fortaleciendo el arraigo de este cultivo en la zona se recomienda implementar talleres para la transferencia de tecnología y la capacitación de productores de banano y plátano, para el manejo de sus plantaciones en términos de sanidad. Promover aún más la implementación de sistemas agroforestales, intercalando las especies propias del bosque mesófilo de montaña (que generan ingresos extra a los productores) con las diversas variedades de bananos y plátano cultivadas en la zona, para así preservar tanto el ecosistema boscoso como aquellas variedades que ya se están perdiendo como el plátano manila y tuna. 